\title{
Fabrication of Antibody Arrays Using Thermally Responsive Elastin Fusion Proteins
}

\author{
By Di Gao, Nicole McBean, Jerome S. Schultz, Ashok Mulchandani, and Wilfred Chen
}

\author{
Supporting Information
}

\section{Experimental Procedure}

\section{A. Glass slide preparation}

The glass slides were coated with a self-assembled monolayer (SAM) formed from octadecyltrichlorosilane (OTS, $\mathrm{CH}_{3}\left(\mathrm{CH}_{2}\right)_{17} \mathrm{SiCl}_{3}$ ) following the procedure described elsewhere. ${ }^{10}$ Prior to the coating process, the glass slides $(75 \mathrm{~mm} \times 25 \mathrm{~mm}$, Fisher Scientific, PA) were cleaned in a piranha solution for 30 minutes, and then rinsed with deionized water. Piranha solution is made by adding $30 \%$ hydrogen peroxide to sulfuric acid in a 3:1 ratio. It should be noted that piranha solutions are extremely energetic and may result in explosion or skin burns if not handled with extreme caution. The slides were completely dried in air before immersed into the SAM solution, made by dissolving $0.5 \mathrm{mM}$ OTS (Aldrich Chemical Co.) into a mixture of hexadecane (anhydrous, Sigma-Aldrich) and chloroform (anhydrous, Sigma-Aldrich) with a volume ration of 4:1. After about 15 minutes of coating in the SAM solution, the slides were thoroughly rinsed by isooctane (Sigma-Aldrich), isopropanol (Fisher Scientific), and deionized water. The static water contact angle on the coated glass slide was $\sim 112^{\circ}$, measured by VCA-optima system (AST Products, Inc.) according to the sessile droplet method.

\section{B. Conjugation of ELP fusion proteins with the antibody and the purification of complexes}

Antibodies from three different mammalian species (rabbit, goat, and mouse) were labeled with fluorophores Alexa 555, fluorescein isothiocyanate (FITC), and Alexa 647, respectively. The rabbit polyclonal anti-E. Coli O157 antibody was purchased from EastCoast Bio, Inc. (ME, USA). The FITC-labeled goat monoclonal anti-E. Coli O157:H7 antibody was purchased from Kirkegaard \& Perry Laboratories, Inc. (MD, USA). The mouse anti-CA 19-9 antibody was purchased from Industries International, Inc. (MA, USA). The fluorophores Alexa 555, and Alexa 647 were purchased from Molecular Probes, Inc. (OR, USA). The rabbit and mouse antibodies were labeled by Alexa fluorophores according to the manual provided by Molecular Probes, Inc. The fluorophore-labeled antibodies were then conjugated with either ELP-ProA, ELP-ProG, or ELP-ProL fusions depending on the host of the antibodies using the following procedure. At $4{ }^{\circ} \mathrm{C}, 30 \mu \mathrm{l}$ of each antibody was mixed with $5 \mu \mathrm{l}$ ELP-protein fusion, both diluted to the concentration of about $1 \mathrm{mg} / \mathrm{ml}$ in phosphate buffered saline solution (PBS buffer, $\mathrm{pH}$ 7.4). The mixture was incubated for 1 hour at $4{ }^{\circ} \mathrm{C}$ before $8 \mu \mathrm{M} \mathrm{NaCl}$ solution was added. The mixture was then incubated at $37^{\circ} \mathrm{C}$ for 5 minutes and centrifuged at $15,000 \mathrm{~g}$ for 15 minutes. The supernatant containing excessive antibodies was recycled. The pellet containing the ELP-protein A, G, or L-antibody complexes was dissolved in $30 \mu \mathrm{l}$ ice-cold PBS, and centrifuged at $4{ }^{\circ} \mathrm{C}$ for $15 \mathrm{~min}$ to remove the undissolved proteins. The supernatant was transferred to a new vial. The purification cycle was repeated once more before the complexes were finally dissolved in $50 \mu \mathrm{l}$ ice-cold PBS.

\section{Printing ELP-ProA, ProG, or ProL-antibody complexes on OTS-coated glass slides using a DNA microarrayer}

Before immobilization, $20 \mu \mathrm{l} 5 \mathrm{M} \mathrm{NaCl}$ solution was added to $50 \mu \mathrm{l}$ complex solutions at room temperature to trigger the ELP domain of the ELP-ProA, ProG, or ProL-antibody complexes to its hydrophobic phase. The complexes were then loaded into a 96-well plate and spotted on the OTS-coated glass slide using a Virtek DNA microarrayer (Bio-Rad) with Stealth Micro Spotting pins (Telechem International Inc., CA). After spotting, the glass slides were immersed in bovine serum albumin (BSA) solution $(20 \mathrm{mg} / \mathrm{ml}$ in PBS) for 2 hours, and then rinsed with warm PBS $\left(37^{\circ} \mathrm{C}\right)$. The glass slides with immobilized antibodies were scanned by a ScanArray Express microarray scanner (Packard Biosciences).

\section{Fabrication of microarray sensors for detection of tumor markers}

The tumor marker cancer antigen 19-9 (CA 19-9) and its capture and detection antibodies were purchased from Fitzgerald Industries International, Inc. (MA, USA). The detection antibody was labeled with fluorophore Alexa 488 (Molecular Probes, Inc. OR, USA). The capture antibody was conjugated with ELP-ProL fusion protein and purified according to the procedure described in section B. The ELP-ProL-antibody complex was printed onto OTS-coated 
glass slides to form $3 \mathrm{X} 3$ arrays according to the procedure in section $\mathrm{C}$. The slides were then immersed in BSA solution $(20 \mathrm{mg} / \mathrm{ml}$ in PBS) to reduce the nonspecific adsorption of other proteins to the surface during the subsequent procedure. After rinsing the glass slides with PBS and dried in air, $5 \mu l$ samples containing different concentrations of CA 19-9 (from 2.1 to $210,000 \mathrm{U} / \mathrm{ml}$ ) were loaded onto the microarray. The slides were incubated at room temperature for 20 minutes in the humidity chamber. PBS was used to wash the glass slide afterwards. Next, $10 \mu l$ detection antibody (diluted to about $0.2 \mathrm{mg} / \mathrm{ml}$ in PBS buffer) was applied to the microarray, and incubated with the slides at room temperature for 20 minutes in the humidity chamber. Finally, the glass slides were washed with PBS, dried in air, and imaged using the microarray scanner. 